\title{
How Many Books Should Be Stored Where? An Economic Analysis
}

\begin{abstract}
The relative advantages and disadvantages discussed are of the remote storage of lesser-used materials in research libraries. Valid decisions on what to store can only be based upon comparing cost of storage with the value of having the same materials at hand. Considerations for such determinations are raised, and formulas are proposed. Several assumptions are made, and appropriate alternatives are delineated.
\end{abstract}

A

s scholars continually explore and write about new areas of learning, major research libraries necessarily grow in size. This growth represents an increase in the corpus of human knowledge, and research libraries make it their task to maintain an inclusive collection of recorded knowledge. New books do not make old books unnecessary.

Growth in knowledge, however, creates problems of both space and bibliographical systems. Buildings and bookstacks are expensive, land for expansion on the central campus becomes scarce, and the books that are relevant to any study become harder and harder to find amidst the multitude of volumes that are not at that moment relevant.

The growth problem will not be engineered away during the next twenty or thirty years by some simple administrative or technological device: subdivision of the library into smaller operating units introduces new difficulties of cost and book-finding; microfacsimile, as of this moment, is more expensive and harder to use than are conventional reading materials; and philanthropic alumni make themselves increasingly scarce as the price of immortality goes up and up,

Mr. Simon is Assistant Professor of Marketing at the University of Illinois. so there is little likelihood of continued expansion without reference to cost.

As a way out of these difficulties, some major research libraries have initiated ,programs of housing the least used books in storage libraries. Such storage libraries are less expensive than conventional stacks due to the compactness of bookshelves, shelving-by-size from one end of the shelf to the other, and employing cheaper land and buildings. The major effect of book storage upon library patrons is that they cannot browse in the stored collection, and they must wait at least a few hours for delivery of the volumes they seek.

But the decision about how many books-if any-should be placed in storage is not at all obvious. A rational decision procedure demands that the librarian balance the cost of the housing ' and maintenance of books against the revenue derived from the use of the books. It is not sufficient merely to compare the costs of different types of storage.

It is a truism of economics that we - maximize the usefulness of an economic system if we maximize "revenue minus costs," or if we minimize "costs plus revenue losses." If we know the cost of housing books in conventional stacks and the cost of housing them in storage, as 
well as the revenue that a particular book will provide when housed conventionally and the revenue that it will provide when housed in storage, we may maximize usefulness if we store all books for which the difference in revenue is greater than the difference in cost. All (!) that we need to know are the costs and revenues relevant to the two types of book housing.

For the revenue side, we shall employ arbitrary estimates of the dollar value of book use, and of the loss of book use in storage, in order that we may consider the library as an independent economic unit. Given those estimates, the specific task of this paper will be to suggest methods of estimating conventional and storage housing costs and ways of using the information to arrive at decisions about placing books in storage or in conventional housing.

\section{Necessary Assumptions}

Some assumptions must be made about general conditions if we are to arrive at any rational solution, but they need not be those that this paper chooses; the reader may, if he chooses, replace them with other assumptions of a similar nature. For purposes of this paper, however, we shall assume that:

1. No research library would desire a more costly type of housing for any of its books than it provides at present in open or semi-open stacks.

2. The upper limit to the budget for housing books of the present collection size, then, will be the cost of housing those books at present. That upper limit is not identical with the total budget for housing books at present, because the total housing budget expenditures may be reduced by weeding out the extra copies and old editions. The assumption in which we are interested, rather, is the upper limit for each physical book, based upon the average cost of housing books in present stack arrangements.

3. Though serials and monographs may have quite different characteristics and value to scholars, our general treatment of them will be as if they were homogeneous. We will indicate how we would alter the mode of solution if we were willing to accept the added complexity of considering them as different commodities. We will deal with subjectarea differences similarly.

4. For the sake of specificity, we will set the problem within the University of Chicago library, and indicate how computations might be made for some part of that library system. The University of Chicago library includes approximately two million volumes at present, somewhat less than half of which are serials.

5. We assume that University of Chicago population will remain constant in the future, and that there will be no change in the future in the external economic environment that would affect the revenues and costs connected with libraries.

6 . We will assume that the librarian can make meaningful estimates of the loss of revenue resulting from the storage of books. At this time we will only assume that revenue-loss statements can be made, and we shall not consider the problem of correct ultimate valuation. We imply simply that whoever estimates the amount of loss, estimates the amount of money that would have to be spent elsewhere in the library or in the university to produce that much revenue, ${ }^{1}$ i.e. usefulness. In other words, we assume that he "knows" the dollar-cost of projects of value to the university equal to the value of additional book uses. It is of crucial importance to recognize that

${ }^{1}$ We must remember that money is not an absolute standard with an intrinsic value against which other things may be measured meaningfully; rather money is an intermediate yardstick, and when you evaluate goods in money units you are really evaluating them against other goods and services that are alternative uses of the money. We may dramatize this by pointing out that whose money is being spent affects the valuation. If the director of the library were to pay for the loss out of his own pocket, he would not only be unwilling, but unable, to appraise the loss per book at more than a few cents. A philanthropist might be able to make an entirely different appraisal. 
at this stage such estimates are arbitrary -but necessary-judgments.

7. On the basis of the results of one portion of the Library Use Study, ${ }^{2}$ we assume that recorded use is a constantmultiple index of all use of books. We also assume that the recorded use is then a constant-multiple index of the value of books. In other words, by this assumption a book that will be used twice in the next five years is worth twice as much as a book that will be used once in the next five years.

\section{Revenue, and Loss of Revenue}

\section{Due to Storage}

The Cost of the Loss-per-Book. We first consider the loss per book that would occur for books placed in storage, over a year's time. Please note the distinction between "cost-per-book" and "cost-per-use" ( or between "loss-perbook" and "loss-per-use"). The loss may be divided into three components:

- (a) $\mathrm{L}_{\mathrm{a}}$, the extra cost of messenger service required to bring a book from the more distant storage library to the circulation desk. $\mathrm{L}_{\mathrm{a}}$ will not include the dollar cost imposed upon the library because it must procure some books from storage that patrons would page themselves if they were in open stacks; patrons' time is required to perform the latter task when the books are housed conventionally. We may estimate the extra cost by multiplying the cost of messenger labor per hour by the extra time required to fetch the book, over and above the time the patron would spend. As a working figure we shall use: ten cents per circulation from the storage library.

To estimate the extra cost per book placed in storage, we multiply the cost per circulation by the probability that the book will be withdrawn during a specified period of time. If the proba-

\footnotetext{
${ }^{2}$ Herman H. Fussler and Julian L. Simon, Patterns of Book Use in Major Research Libraries (Chicago: University of Chicago Library, 1961).
}

bility that a given book will be withdrawn during a year is 0.01 , then the estimated extra cost of messenger service is 10 cents $\times .01$, or a tenth of a cent per year.

(b) $\mathrm{L}_{b}$, the loss of revenue due to the patron's irritation and impatience at having to wait, plus the loss from possible interferences with his research because he must wait four to twenty-four hours to have the book in his hands. If we take one dollar per use as a working figure, on the average, then the estimated cost per year for a book with a probability of 0.01 uses per year is one cent.

(c) $\mathrm{L}_{\mathrm{c}}$, the loss due to the loss of some uses of the book that would have "occurred if patrons had had an opportunity to find the book through browsing. Library Use Study data suggest an upper limit on how much use would be in jeopardy if given books were placed in storage: perhaps one-half of their total valuable use (an estimate that is probably on the high side) would be lost if 25 per cent of the books in economics and Teutonic languages and literatures were placed in storage. (Of course if storage plans went into effect, readers would learn how to browse through catalogs, and less of the valuable use would be lost thereafter.) If we place a value upon each valuable use lost, say five dollars per use, and multiply that by one-half of the total expected use, we may estimate the use that will be lost. For a book with an estimated recorded use of 0.01 per year, the estimated loss per year would be two and a half cents.

Note that the director of the library may insert any dollar figures that he feels circumstances warrant in place of the above working figures. He may also substitute schedules of different valuations for different groups of books. $\mathrm{He}$ may wish to say that the value of a lost use of a serial is sixteen dollars, while the value of a lost use of a monograph is four dollars. He may set up schedules 
TABLE 1

Expected Revenue Loss of Various Groups of Economics Trtles

\begin{tabular}{c|c|c|c|c}
\hline \hline $\begin{array}{c}\text { Groups of } \\
\text { Titles Ranked } \\
\text { by Expected } \\
\text { Use }\end{array}$ & $\begin{array}{c}\text { Expected Use } \\
\text { Per Title } \\
\text { Year in } \\
1961\end{array}$ & $\begin{array}{c}\text { Expected Use } \\
\text { Per Title } \\
\text { Year in } \\
1966\end{array}$ & $\begin{array}{c}\text { Expected Use } \\
\text { Per Title } \\
\text { Year in } \\
1976\end{array}$ & $\begin{array}{c}\text { Expected Revenue } \\
\text { Loss Per Title in } \\
1961\end{array}$ \\
$\begin{array}{c}\text { Lowest 25 Per Cent } \\
25-35 \text { Per Cent }\end{array}$ & .0200 & .0190 & .0170 & $\$ 3.60 \times .02=\$ .072$ \\
36-50 Per Cent & .0500 & .0285 & .0255 & $\$ 3.60 \times .03=\$ .108$ \\
& .0500 & .0475 & .0425 & $\$ 3.60 \times .05=\$ .180$ \\
\hline
\end{tabular}

for different subject areas, or for any group of books that he wishes to consider as homogeneous. But it rather obviously would not be feasible for him to set a different value for each of the hundreds of thousands of books that would be likely to go to storage.

The extra cost of messenger service, $\mathrm{L}_{\mathrm{a}}$, and the cost of waiting, $\mathrm{L}_{\mathrm{b}}$, are certainly proportional to the use. By our assumptions, the loss of use is also proportional to recorded use. We may, therefore, say that the total expected revenue loss for a book is proportional to its expected recorded use. By our working figures, the loss would be three dollars and sixty cents for each expected recorded use.

The Total Loss for Groups of Books Sent to Storage. The sum of the expected losses for a group of books is the average probability of a book being used multiplied by the value of the loss, multiplied by the number of books in the group.

The Library Use Study provides data for the estimated probability distribution of the use of books going to storage. ${ }^{3}$ (But as we have said, we can provide no data that helps to place a value upon the cost of waiting.) Table 1 presents such data for a small segment of the collection, the economics monographs. The expected use of various groups of economics books, of which the expected revenue loss is a function, is based in

\footnotetext{
3 That use is the use that would occur if the books were to remain in the stacks. But recorded circulation from storage will necessarily be higher because there can be no non-recorded use in the storage stacks. As a working figure we might estimate that recorded circulation will rise 25 per cent for books sent to storage. We will discuss the estimates as if that correction has already been made.
}

large part upon the number of years since the last use of the book. Note that these data include only titles held by the library at present.

Summing the Revenue Loss for All Time Periods. Library Use Study data also suggest that for those books likely to be placed in storage (from the University of Chicago library with its presently constituted collection), little further obsolescence is likely to occur. Therefore, we assume that the revenue in each period will be the same as in the first period, a helpful bit of simplification. The "present value" 4 of the total revenue loss would then be the value of an annuity of equal sums paid in each year (assuming an appropriate rate of interest).

Costs of Housing Books in Conventional Stacks and Storage Buildings

Conventional Housing Space Costs. Some of the costs of book housing depend upon the cubic space allowed for books, no matter what proportion of the space is being filled. Therefore, the foundation for estimates of housing costs, in both storage and conventional housing, is the cost of space.

In his article on library cost accounting, Rider ${ }^{5}$ lists these items as being relevant when computing space costs:

1. interest on the investment which was made in the building;

2. depreciation and obsolescence accruing on it; insurance on it;

3. heat and light expenditures;

\footnotetext{
4This is the relevant economic value of the loss.

"Fremont Rider, "Library Cost Accounting," The Library Quarterly, VI (October 1936), 331-81.
} 
4. janitorial labor;

5. janitorial expenses and supplies;

6. building repairs.

The computations, of course, must be different for storage and conventional housing.

For existing conventional housing, items (1) and (2) will be the most troublesome to establish. Original construction figures are without any meaning fifty years, say, after construction of the building. And the "opportunity cost" of land on a campus is difficult to estimate.

In the long run, conventional bookhousing space can be converted into other university uses, such as office space. So the relevant cost per cubic foot for conventional housing "rent" may be approximated by the present cost of new office or library construction on land of similar value to the university. We may estimate the value of the land by referring to the cost of land purchased in the immediate vicinity at this time. It is important to note that this component of the cost of book housing will vary greatly from library to library, depending upon the urban or non-urban location of the campus and library. But it is unlikely to be a major cost factor.

Naturally, the cost-per-year must be arrived at by means of an appropriate depreciation scheme and the choice of a proper rate of interest on the investment. The treasurer of the university should be in the best position to set the appropriate rate of interest. (A Chicago realtor has suggested that a working figure for the cost of rent ( 1 and 2) in conventional housing in Chicago might be $\$ 1.25$ per square foot per year exclusive of costs of shelving.)

For conventional housing we may estimate Rider's items (3) through (6) from present library maintenance records. Rider says that Wesleyan measured the cubic footage of all spaces within

- The opportunity cost is the dollar value of the best alternative use-usually sale on the open market $\multimap$ of the land. It is the most sensible way of estimating a value. the library building that were maintained on the library maintenance budget, and then attributed costs to book housing in proportion to the amount of cubic space books occupied. This procedure makes good sense. A fair estimate might be fifty cents per square foot.

Costs of Space per Book Housed in Conventional Housing. Costs of Shelving and Fixtures.

After computing estimates of cost per cubic foot from the cost of rent plus the cost of maintenance, we convert into cost of space per housed book. We must first attribute some part of the cost of shelving and other fixture to each physical book. The estimates of these costs depend not only upon cubic foot costs, but upon book-size, book and shelf arrangement, and proportion of capacity to which the conventional or storage space will be filled on the average day in the period. Once we have calculated the number of volumes that will be housed in a given space (see next few paragraphs) the calculation of costs is trivial.

Shifting Costs, and Conventional Stacks Capacity. The necessity of shifting parts of the collection in order to make room for new accessions prevents a library from shelving books solidly from one end to the other of every shelf. Instead, the library disperses its holdings throughout the shelves in such a manner that most new accessions will not overflow the capacity of the shelf on which they will be placed.

At perhaps 80 per cent of shelf capacity $^{7}$ it becomes necessary to begin shift-

"Shelf capacity itself is not a clearcut, easilymeasured concept. It is something less than the linear measure of shelving in the presently constituted stacks, the "something less" being made up of (a) the space lost because the discrete volumes will never add to exactly the width of a single shelf; (b) the space lost because it is desirable to have the several volumes of a multi-volume work on the same shelf; (c) some space that must be allowed for books to slip easily off and onto the shelf, in order that the books should not be damaged by readers; (d) space required for flexibility because books are of unequal height. We might attempt to estimate shelf capacity by saying that if the books in the collection were measured in width sideby-side, they must measure no more than 95 per cent of the linear shelving. 
Fig. 1. Costs of Housing, Revenue Loss \& Shifting of Books at Various Capacity Levels

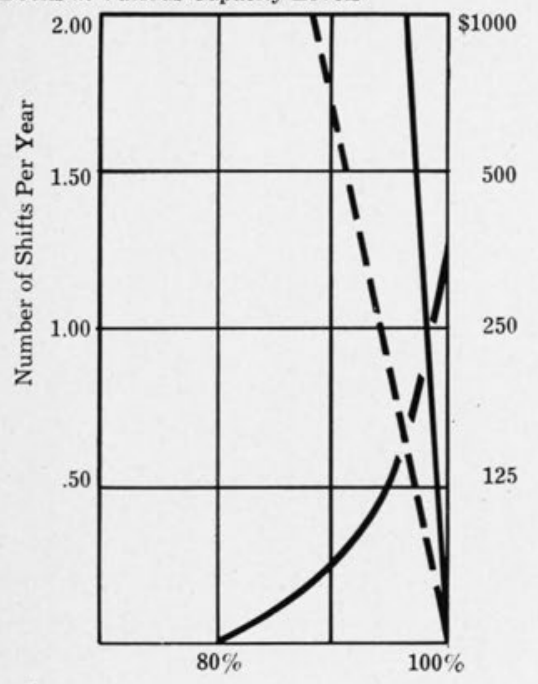

Sum of the Cost of Storage

- Housing \& Revenue Loss at $7 \notin+4 \ell=11 \notin$, Assumes Constant Weeding

Extra Cost of Conventional Housing at 20\& per Book for the Residue Less Than $100 \%$

The $80 \% \& 90 \%$ Shifting Cost Points Are Based on an Estimate by Stanley Gwynn. The Rest of the Curve Is Extrapolated.

ing sections of books en masse. ${ }^{8}$ At some point-which we shall proceed to determine-the increasing amount of shifting necessarily becomes greater than the money saved by the increased utilization of space.

We may estimate when this decision point will occur as follows: Assume: (1) a particular subcollection consists of one hundred thousand homogeneous volumes; (2) the mean rate of accessions will be twenty-eight hundred volumes per year for this area for at least the

\footnotetext{
${ }^{8}$ The author appreciates the advice of Stanley E. Gwynn in developing this estimate. Mr. Gwynn is assistant director for reader's services at the University of Chicago.
}

next five years; $;^{9}$ (3) at 90 per cent capacity it costs twenty cents per year to house a book in the conventional stacks; (4) at the expected average capacity level it costs seven cents (six cents for space plus one cent for transfer) to house a book in warehouse storage per year; (5) to shift one hundred thousand books in an operation that requires moving them from shelf to cart to shelf costs 0.5 cents per book, or five hundred dollars. ${ }^{10}$ At 90 per cent capacity one-fourth of the collection must be shifted each year to meet new accessions, and at 95 per cent, one-half of the collection must be shifted each year to meet new accessions, while no shifting is required at 80 per cent capacity. A smooth curve of the relationship between capacity-level and shifting costs may be seen in Figure 1 . The vertical distance may be read in terms of the amount of shifting per year required at a given capacity level, or the dollar cost of that much shifting for a collection of one hundred thousand books.

The sloping straight lines in Figure 1 may be read as the cost of storing (100$\mathrm{x}$ ) per cent of a collection of one hundred thousand books. If a policy decision resulted in a 90 per cent capacity level, the relevant cost is the cost of storing 10 per cent of one hundred thousand books elsewhere. One of the lines shows the cost of housing books in conventional stacks, the other the cost of housing books in storage warehouses.

The optimizing point is that point at which the cost of housing another book somewhere else first exceeds the extra cost of shifting that would have to be paid if the book were kept in the central collection.

The diagram makes it clear that the cost of shifting books is insignificant . relative to the cost of housing fewer books in conventional stacks, in order to reduce the amount of shifting. This con-

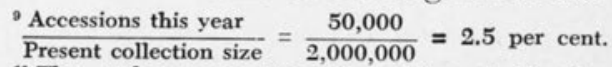

${ }_{10}$ The author appreciates the advice of Kingsley Miner in developing this estimate. Mr. Miner is head
} of stacks at the University of Chicago. 
clusion of course depends upon the estimates of shifting cost and amount of shifting required; the estimates might well require empirical validation. But in any case it is probably fair to say that the equivalent of one complete shift each year is the most that would be required under any policy. It would therefore behoove libraries to allow their conventional stack capacity to range from almost 97.5 per cent to almost 100 per cent each year if accessions would equal 2.5 per cent, and if removals to storage would be the same. Perhaps in practice they would fall slightly below these figures, but the cost of varying 1 per cent or so would not be worth the computing or considering.

The diagram also suggests that institutions that will build new conventional stacks, without reference to storage plans, might do well to house books at almost full capacity in some parts of the available stack space while using other parts of the stack space for office and other purposes, rather than spreading books over the entire available space. As more space would be needed office space could be gradually converted to book space and the cost of the conversion (if planned in advance) would probably permit such a procedure. This should result in important savings if a new library is built with stacks to contain twice the number of holdings at the time of building. ${ }^{11}$

Effect of the Storage Program on Costs of Space per Book. Now if we assume that $\checkmark$ the average effective working capacity for conventional housing is 98 per cent of shelf capacity, we can easily compute the space requirements and costs for the average book. It will be simply: the cubic space per shelf (including aisle space,

11 Wilson and Tauber in their book The University Library (New York: Columbia University Press, 1956), p. 467, quote with approval Gerould's suggestion (The College Library Building, Its Planning and Equipment (Chicago: ALA, 1932), that "the stack be planned to contain shelving for double the number of books contained in the collection when the building is opened." etc.) $\times \frac{\text { average book width }}{\text { shelf length }} \times \frac{100}{98}$. The cost of space per book in conventional housing, then, follows from a combination of the cost-per-cubic-foot estimate and the cubic-inches-per-book estimate. ${ }^{12}$ Let us take 20 cents per book-year as our working figure.

Note that as soon as a library makes provision for storage housing it lowers the cost of conventional housing. Without a storage building, conventional stacks can never be filled to effective working capacity, since their physical expansion must be in fairly large discrete units. A storage library would permit the conventional library to remain much nearer to 98 per cent, because physical expansion can be more continuous for the storage library.

The Cost of Storage Housing. Empty Space Costs in Storage Housing. The cost for a square foot (or cubic foot) of new storage library housing is considerably less than that for conventional housing, primarily because of cheaper land and building costs. If $\$ 1.25$ per square foot is the appropriate "rent" figure for conventional housing, 85 cents may be appropriate for a storage library. The costs of maintenance per cubic foot would also be substantially lower in storage housing. It is unnecessary to maintain a standard that will allow patrons to browse and read in comfort. Nor will there be as high custodial costs, since use is less frequent.

The cost of storage space would be somewhat different if some existing library space were converted to storage use, rather than building warehouses for the stored books.

Space Costs per Book in Storage Housing. On the basis of book-size surveys, and the experience of other libraries with compact storage, it is possible to estimate the space required for the average book

\footnotetext{
12 Library space costs are ordinarily computed on a square-foot rather than cubic-foot basis, but the conversion from one system to the other should present no problems.
} 
Fig. 2. The Marginal Revenue Curve for Economics

Monographs When Ranked from Lowest to Highest Expected Use

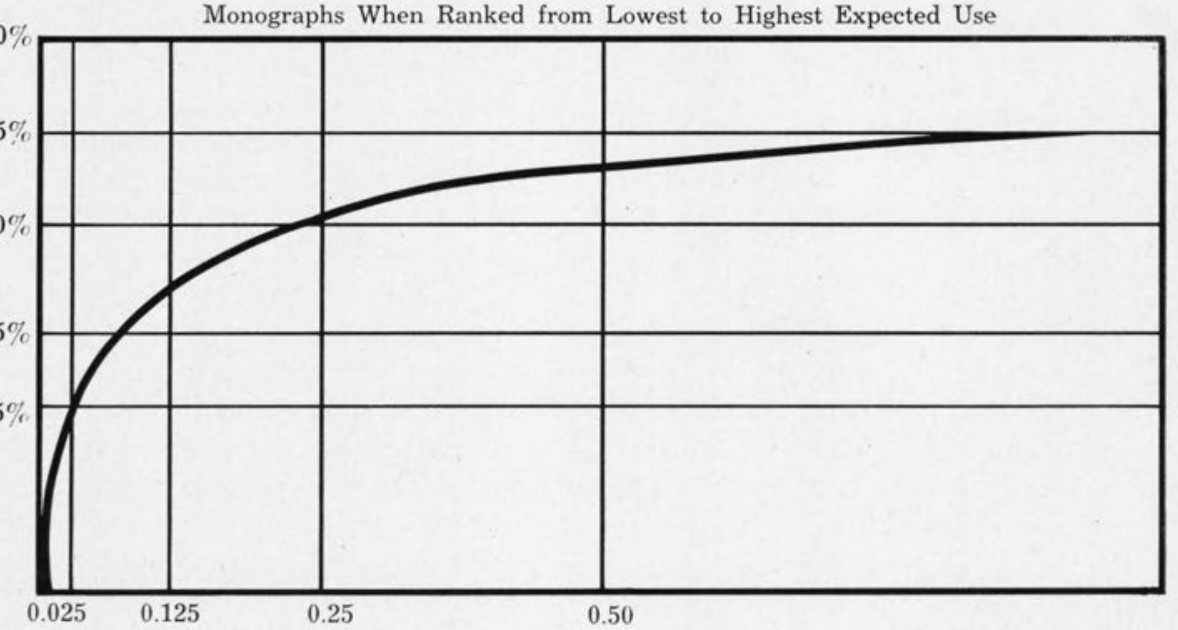

Expected Yearly Use of Any Group of Books

$\$ 4 \$ 2 \$ 1$

$\$ 0.25$

Loss Attached to Each Use That Would Have Been

Received If the Book Had Not Been in Storage, in Dollars

in storage housing. But a storage building will never be quite full. The likely plan is for frequent space additions to the storage building, and the amount of unfilled space at an average time between space additions will depend upon decisions concerning the size and frequency of additions.

Given estimates of empty space costs, maintenance costs, amount of space required by the average book, and mean amount of unfilled space, we may compute the cost of housing books in storage. We may take six cents per book per year as a working figure.

Costs of Transferring Books to Storage. Another component that affects the relative costs of conventional and storage housing is the cost of transferring books from conventional to storage housing. This cost applies of course only to books already within the library system, and not to new accessions.

To transfer a book requires three, kinds of labor.

(1) Choosing the books for transfer. We assume that this would be done clerically on the basis of statistical rules.
(2) Physically transferring the books from one location to another.

(3) Altering catalog cards to reflect the new location of the book.

There are two sources of cost data for this transfer cost: Yale's Selective Book Retirement Program, and an exploratory study by Kenneth Soderland (in association with the Library Use Study). Together, they suggest twenty-five cents per title as a working figure. Multivolume titles and serials reduce the costper-book considerably. Library Use Study data can estimate the numbers of physical book units per title, separately for monographs and serials, in order to get unit costs. We might take as working figures sixteen cents per monograph volume, and ten cents per serial volume. To find the cost relevant to storage considerations we must, of course, allocate part of this cost to each of the years that the book will remain in storage. Assume that the extra cost is one cent per volume per year.

Naturally, the cost of transfer must be a function of the lot size being transferred. The figures estimated above are 
for lots sufficiently large that no further economies can be effected. ${ }^{13}$

\section{First Approximate Solution to Storage Decision}

If our estimates of cost are satisfactory, we may now formulate decision rules for the simplest possible case. Such a simple case would be one in which (1) the library would accession no more books, (2) any extra conventional stack space would be converted to other purposes such as offices, and (3) the interests of the reading population would remain the same in the future. A collection of books in a discipline that has ceased to produce new work-alchemy, perhapsmight come close to this case.

We begin by constructing a graph like Figure 2. The curve plots data similar to that found in Table $1 .{ }^{14}$ Revenue is expressed in terms of expected uses per year of a group of books. We may read from the curve that if we rank books in economics by predicted use from low to high, the group of books that is less than 25 per cent of the curve from the bottom have an expected use of .025 uses per year.

If a library administrator employed fourteen cents per book-year as the cost difference between conventional and storage housing (exclusive of $\mathrm{L}_{\mathrm{a}}, \mathrm{L}_{\mathrm{b}}, \mathrm{L}_{\mathrm{c}}$ ), he would store any book for which expected use multiplied by the value of an expected use would equal less than fourteen cents. From the graph we may establish what portion of the books should be sent to storage on the basis of any assumed valuation. For example, an assumed valuation of two dollars per year would rationally send books to storage whose expectation of use is less than $1 / 15$ use per year $(\$ 2 \times 1 / 15=\$ .14)$, and we see that under that valuation approximately the bottom 35 per cent should go to storage.

\footnotetext{
is In economic terms, the marginal cost curve is that of that point and beyond.

${ }^{14}$ It is a marginal revenue curve.
}

\section{INTERACTIONS AND FUNCTIONAL RELATIONS IN THE SOLUTION}

It should be obvious that all statements made about costs in the previous paragraphs are gross simplifications. In fact, all costs must be related to types of book housing, lot sizes, and choices of procedure, as well as to revenue schedules and assorted policy decisions. It will perhaps be most illuminating if we now discuss a few prototypical examples of problem situations, considering the revenue and cost variables at the same time. We will discuss a small, self-contained portion of the collection that has grown to the point where it is economical either to store part of the subcollection, or to build further conventional housing for part of this subcollection. This discussion necessarily will ignore many complicated interrelationships.

We assume that we have established that a sizable portion of the one hundred thousand volumes in economics-perhaps 26 per cent of them-are appropriate for storage, by a first approximation of the difference between their revenues in conventional housing and in storage, as compared to the difference in cost between those two types of storage. We then face two alternatives: (a) build new storage housing for the books to be stored; or (b) pull the books to be stored from the shelves, shift the remaining conventionally-housed books closer together, and store some books compactly in space made by compressing the conventional books. For the moment, we shall make the unrealistic assumption that the cost of storage space would be the same under both alternatives. In practice this would not be the case since new storage housing would provide more shelf space per square foot of floor space than would conventional housing, and the ground rent would be lower.

Building New Space for Storage. Let us look first at the economic ramifications that follow if we remove books to new storage facilities. Under this plan some 
part of the subcollection is removed in order to make room for new accessions.

It is important to note that, though 25 per cent of the subcollection may be candidates for selection for storage, there is no gain in moving any more of them to storage than is justified by some reduction in operating costs or by elimination of the cost of new conventional storage space for new accessions. To illustrate, removing 25 per cent of the collection to new storage immediately would impose the new cost of storage housing for them, and there would be loss of revenue $\mathrm{L}_{\mathrm{a}}$, $\mathrm{L}_{\mathrm{b}}$ and $\mathrm{L}_{\mathrm{c}}$. But the space that they left vacant in the conventional stacks would not be filled for several years by new accessions. The space in the conventional stacks would still have a cost, whether it were full or not.

It would seem logical, then, to remove only enough of the existing collection to make room for new accessions unless the cost of working with such small lots were greater than the loss of revenue and the cost of storage. The only transfer cost that changes with the lot size is the cost of selecting titles. Recataloging costs per title are quite constant.

The cost schedule of transferring monographs might look like this:

\section{Total Cost of}

\section{Lot Size}

Transferring Lot

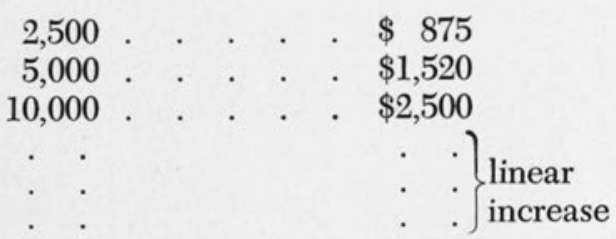

We may then look at the total costs related to two storage plans: (1) trans- ferring 2,500 titles each year, and (2) transferring 5,000 titles each two years.

It appears, then, that if: (1) the cost schedule for transferring books shows no greater economies of scale than we have estimated (and the opposite is likely to be true), and (2) the library added storage space each year, then the library would find that it was most economical to move lots no larger than one year's accessions at a time.

Naturally enough, if a library were even larger than 100,000 books, the same conclusion would be even more inevitable. ${ }^{15}$

On the other hand, if a library unit were much smaller than 100,000 titles it would at some point be economical to store books only biennially, tri-ennially, or even once in ten years. It is here that we put to good use the notion that obsolescence among very old books is not very great: it is just as costly in loss-ofreader revenue to store one thousand books from each of two branch libraries as it is to store two thousand books from one of them.

Converting Some Existing Space to Storage Housing. There is also a distinct set of lot-size alternatives if the library decides to utilize existing space, at least temporarily, for compact storage space. In this case the cost of the shift of books necessary to compress the books each time a lot is removed for storage must also be considered. Since all costs including loss of reader revenue are the same as in the new storage space alter-

15 The marginal cost of transfer would become constant, while the loss-of-reader-revenue and costs-ofhousing are constant-multiple functions of collection size.

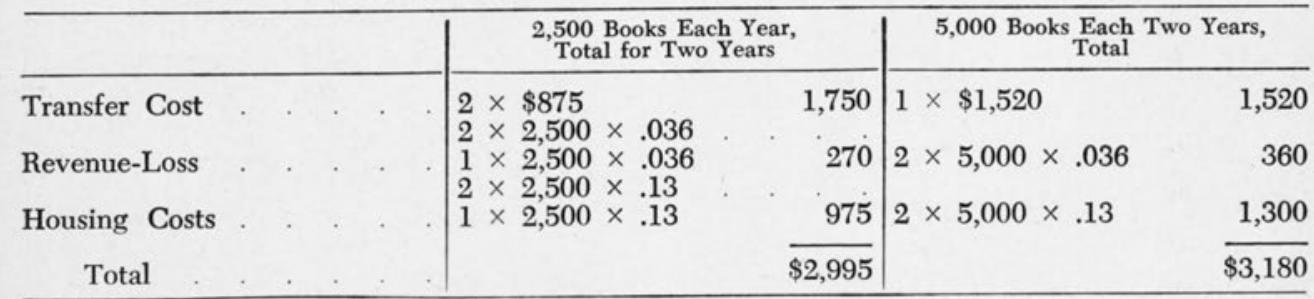


native except for, (a) the extra cost of "compressing" the remaining books to make space for new accessions, and (b) an extra cost of retransfer to other storage facilities at some later date, the optimum lot size must be larger than if new space is to be built. But in any case the lot size must be at least the number of accessions if old space is to be converted. For example, removing five thousand books and storing them compactly into the room that twenty-five hundred books require when housed conventionally leaves room for twentyfive hundred new accessions.

Removing five thousand books each year means an extra full shift each year to compress the books. The extra shifting cost is $\$ 500$ for the one-year period, as compared with a housing storage cost of $5,000 \times \$ .11=\$ 550$. There appears to be a very slight advantage to old-stack storage as opposed to storing a book lot of that size in new storage facilities. But the retransfer cost would probably eliminate any strong advantage.

On the other hand, if we remove ten thousand books at once, the total compression shifting cost is the same as for five thousand books. The proper comparison is therefore between $\$ 500$ extra cost of shifting for the two-year period, against $\$ 10,000 \times .11$, or $\$ 1,100$, which would be the cost of storing those books for two years in new storage facilities. It - therefore is cheaper to compress books and make room for large lot sizes than it is to build new storage buildings immediately.

Note that in any case the number of books stored in converted conventional housing must inevitably become zero in some relatively short time, the length of which will depend on the loss of reader revenue schedule and the rate of obsolescence. If 25 per cent of the existing collection falls into the "storage" category in the next thirty years, then in ten years the new accessions for the exemplar library we constructed will force all stored books out of converted conventional housing and into new storage facilities. This suggests that under most conceivable sets of conditions, libraries would not make space in conventional housing for compactly stored books.

\section{Requirements for a General Solution}

The foregoing discussion indicates that a general formal solution to the problem is beyond the scope of this paper. There are several more sources of complexity: (1) a library system is composed of many discrete branch libraries, all of which are filled to different capacity levels at any starting time; (2) the revenue losses vary greatly from subject area to subject area; (3) some new accessions would go directly to storage; (4) lot sizes are discrete, probably with large jumps between possible sizes.

A list of the major variables should be of interest to directors of libraries:

1. The number of books acquired in year $1,2,3, \ldots$. Estimated directly by the director of the library. Perhaps more or less constant at sixty thousand for the University of Chicago at present.

2. The cost of storage housing in year $1,2,3, \ldots$. This is a constant-multiple function of the number of books stored, and we may estimate six cents per bookyear. A more precise solution would allow perhaps ten cents for storage in space formerly allotted to conventional housing.

3. The cost of conventional housing in year $1,2,3, \ldots$. It is a constant-multiple function of the number of books housed, and the capacity level. As a working figure we may choose twenty cents per book-year at 98 per cent capacity.

4. The cost of transferring books to storage from convention housing in year $1,2,3, \ldots$. It includes costs of selection and recataloging. It is a function of the total number of books as well as the number transferred in a lot. 
5. The cost of shifting books closer together to make space for compactly stored books in year $1,2,3, \ldots$. It is a function of the number of shifts to be made, and the number of books.

6. The cost of shifting books to accommodate new accessions in year $1,2,3, \ldots$. It is a function of the number of shifts as well as the number of books to be shifted.

7. The cost of present amount of conventional housing space for a year.

8. The loss of revenue from books placed in storage in years up to and including $1,2,3, \ldots$. It is a function of the number of books stored, the probability distributions of their expected use, and the schedules of value attached to the loss of use.

We wish to minimize the total costs, including loss of reader revenue, for some specified number of years into the future. (Properly, we discount the cost in future years by the appropriate rate of interest.) All values in the equations to be solved are functions of constants, or of the numbers of books to be stored in each period in new storage housing and in converted conventional housing. We therefore wish to seek the number of books to be placed in each type of housing.

As a practical matter, the director of a library would undoubtedly have to fix as constant many of the variables we have defined, and will find himself faced with a severely limited set of alternatives. For example, he may constrain the system to store an equal number of books each year in order that he may stabilize a work force. Or he may have available a large amount of empty conventional housing space. Or some branch library may be at the bursting point while others are nowhere near capacity. With such a restricted range of choices it should not be impossible or too arduous a task to estimate the values of the variables we have defined and to find the best choice of alternatives.

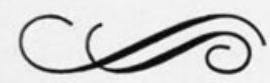

